\title{
O USO DA EDUCAÇÃO A DISTÂNCIA E DOS AMBIENTES VIRTUAIS DE APRENDIZAGEM NA IMPLEMENTAÇÃO DE POLÍTICAS PÚBLICAS NO BRASIL
}

\author{
SÃO PAULO/SP MAIO/2018
}

\author{
Edward dos Santos Netto - UNICSUL - edwardnetto@yahoo.com.br \\ Cristiane Camilo Hernandez - UNICSUL - cristiane.camilo@cruzeirodosul.edu.br \\ Tipo: Investigação Científica (IC) \\ Natureza: Relatório Final de Pesquisa \\ Categoria: Pesquisa e Avaliação \\ Setor Educacional: EDUCAÇÃO SUPERIOR
}

\begin{abstract}
RESUMO
O artigo tem como objetivo tratar sobre a importância da utilização dos ambientes virtuais de aprendizagem e da Educação a Distância para efetivação de políticas públicas no Brasil. Para isso, inicialmente, foram feitas algumas considerações a respeito da educação a distância e dos ambientes virtuais de aprendizagem. Em seguida, foram definidos conceitos de Políticas Públicas e feitas algumas ponderações sobre a implementação dessas políticas com o apoio dos ambientes virtuais de aprendizagem. A título de exemplo, foram feitos relatos, sobre a utilização de ambientes virtuais de aprendizagem para implementação de políticas de segurança pública e saúde. Foram apresentadas algumas limitações do uso dos ambientes virtuais de aprendizagem. Ao final, conclui-se que os ambientes virtuais de aprendizagem utilizados em educação a distância, embora com alguns desafios e limitações, são úteis e importantes para a implementação das políticas públicas nacionais.
\end{abstract}

Palavras-chave: Ambientes virtuais de aprendizagem, Educação a distância, Políticas Públicas 


\section{INTRODUÇÃO}

A Educação a Distância (EaD) é uma forma de transmissão de conhecimento, onde os responsáveis pelo ensino, tais como professores, tutores, etc., em regra, se encontram separados de seus alunos, no espaço e no tempo. Por isso, o ensino é mediado e as mídias, diversas. Neste contexto, atualmente, a Internet toma lugar preponderante, pois acarreta facilidade para disseminação de áudio, imagens e documentos em ambientes virtuais de aprendizagem (AVAs).

Cabe dizer que a EaD é muito importante para melhorar as políticas públicas ligadas à educação, visto que permite ampliar o acesso ao ensino ao vencer barreiras como as distâncias geográficas, falta de disponibilidade de tempo e até mesmo barreiras econômicas, pois geralmente reduz custos. Porém, além disso, é possível perceber que as características dos AVAs, utilizados em EaD, podem ser úteis na concretização de políticas públicas voltadas a outras áreas, como saúde, segurança, previdência social, dentre outras.

Destarte, o presente artigo é relevante por expor a utilização dos AVAs e da EaD para concretizar políticas públicas de diversas áreas sociais e não somente políticas públicas de educação. Assim, o artigo indica que a utilização de AVAs combinados com uma metodologia de $\mathrm{EaD}$ permite criar alternativas para os entes públicos levarem a efeito suas políticas e consequentemente atender melhor ao interesse público. Contudo, é necessário questionar: Quais os desafios e as limitações da utilização de AVAs para a concretização de políticas públicas? Como a utilização de AVAs pode contribuir para a efetivação de políticas públicas?

\section{METODOLOGIA}

A presente pesquisa classifica-se, quanto à forma de abordar o problema, segundo os ensinamentos de Richardson et al. (2007 apud Zanella, 2009), como qualitativa, caracterizadas, em geral, pela não-utilização de instrumental estatístico na análise dos dados, exceto quanto às referências feitas a pesquisas pré-existentes. Já em relação aos objetivos, essa pesquisa é classificada como descritiva, pois nela, os fatos são observados e descritos sem interferência do pesquisador (Prodanov e Freitas, 2013).

No que tange aos procedimentos, essa é uma pesquisa bibliográfica, na qual são examinados livros, artigos e estudos anteriores relacionados ao tema em análise. A presente pesquisa, quanto aos procedimentos técnicos, se classifica também como documental, tendo em vista que analisa normativos e relatórios e dá a eles interpretação 
útil aos objetivos do trabalho (Prodanov e Freitas, 2013)

Os dados foram coletados em consultas a artigos disponíveis na Internet, consultas a textos legais e normativos e a livros considerados relevantes no período de 2017 a 2018. Os dados foram buscados em fontes consideradas confiáveis e organizados de forma a se ter, primeiramente, uma visão abrangente do que são os Ambientes Virtuais de Aprendizagem (AVAs) utilizados na educação a distância e suas potencialidades. Em seguida, buscou-se estabelecer o conceito de "Políticas Públicas" a ser utilizado no presente trabalho. Posteriormente, foram apresentados exemplos de utilização dos AVAs para implementação de políticas públicas e abordadas algumas limitações de seu uso frente as necessidades sociais até a conclusão do artigo.

\section{OS AMBIENTES VIRTUAIS DE APRENDIZAGEM}

Os AVAs são criados por sistemas computacionais que agrupam várias ferramentas para permitir a mediação em Educação a Distância (EaD). Estes sistemas possibilitam a criação de um âmbito no espaço virtual onde ocorre o ensino e a aprendizagem. Ressalte-se que o conceito de AVA é mais amplo que a simples disponibilização de conteúdo instrucional através de uma página Web. As ferramentas de interação possibilitam cenários para trocas sócio-cognitivista entre os agentes da EaD. (NUNES et. al., 2016).

Mediante a utilização dos AVAs é possível criar atividades para os alunos com a finalidade de criar e disseminar o conhecimento. Estas atividades podem fazer com que os alunos se comprometam com seu auto aprendizado e podem criar um ambiente de cooperação para uma aprendizagem coletiva. Portanto, os AVAs podem ser muito úteis para atender as novas demandas de uma sociedade em transformação em que há necessidade de constante aprendizagem, tanto para os indivíduos como para as organizações. Por isso, tais ferramentas podem contribuir para melhoria da vida em sociedade ao auxiliar a efetivação de políticas públicas.

\section{CONCEITO DE POLÍTICAS PÚBLICAS}

O tema Políticas Públicas, como área do conhecimento e disciplina acadêmica, nasceu nos Estados Unidos da América sem estabelecer relação com as teorias sobre o papel do Estado, passando direto à ênfase sobre a ação dos Governos (Souza, C., 2006). É válido dizer que "Política Pública" é um ramo da Ciência Política que possui suas próprias modelagens, teorias e métodos, mas que pode ser objeto de disciplinas como a Filosofia, a Psicologia, a Sociologia, a Economia e outros (Souza, C., 2003). 
Souza C. (2006) apregoa que não existe uma única, nem melhor, definição sobre o que seja política pública. Assim, pode-se dizer que Políticas Públicas são o conjunto de ações governamentais destinadas a atender as necessidades ou os interesses do povo politicamente representado ou o ramo da Ciência Política que estuda estas ações.

As políticas públicas podem ser voltadas aos mais diversos setores da vida em sociedade e por isso são comuns referências às políticas públicas de educação, políticas de segurança pública, políticas públicas de saúde e outras.

\section{A UTILIZAÇÃo DE AVAs NA IMPLEMENTAÇÃO DE POLÍTICAS PÚBLICAS}

$\mathrm{Na}$ análise das políticas públicas, a "implementação" pode ser vista como parte ou fase de um ciclo, em uma abordagem chamada "sequencial" ou "ciclo de políticas públicas". Lima e D'Ascenzi (2013) citam que este modelo sequencial de análise das políticas públicas é composto pelas fases: formulação, implementação e avaliação. Relatam, então, que a implementação se refere à execução das decisões tomadas na etapa prévia.

Assim, após o Governo decidir por adotar uma política, deverá colocá-la em prática, ou seja, fazer com que ela tenha efeitos na vida das pessoas individualmente e da sociedade como um todo. Nesse rumo, Rua (2009) simplifica outros conceitos ao explicar que "a implementação consiste em fazer uma política sair do papel e funcionar efetivamente".

A utilização dos AVAs na implementação de políticas públicas da área de educação já é bastante difundida no Brasil, tendo em vista as características geográficas do país, o contexto social, o atual estágio do desenvolvimento tecnológico e até mesmo a existência de importantes normas jurídicas que regulamentam a EaD em nosso território.

É possível constatar, também, que políticas de educação repercutem nas demais políticas sociais. Em geral, mais educação tende a diminuir a criminalidade, melhorar condições de saúde, aumentar consciência sobre o meio ambiente, garantir melhores condições de trabalho às pessoas, dentre outras decorrências. Destarte, a utilização de AVAs com uma metodologia EaD tem o potencial melhorar e dar suporte à implementação de políticas públicas de várias áreas sociais, como nos exemplos a seguir.

\section{Segurança Pública}


A utilização de AVAs na implementação de Políticas Públicas de Segurança pode ser observada sob vários aspectos. Por exemplo, o Ministério da Educação (MEC) reconhece cursos superiores de segurança pública em grau de bacharelado e tecnológico que são ofertados na modalidade EaD. Estes cursos permitem capacitar profissionais para desempenhar melhor suas funções, tendo em vista que permitem aos alunos conhecer ou aprofundar seus conhecimentos em questões gerenciais, legais, éticas e técnicas da segurança pública.

Além dos cursos acadêmicos, existem cursos e treinamentos ofertados pelos entes públicos aos seus agentes de segurança, como é o caso da Polícia Militar do Estado de Minas Gerais (PMMG). Além do treinamento das forças de segurança, a importância da EaD para a implementação das políticas públicas de segurança também é visível no que concerne ao cumprimento das penas e à realidade que envolve o sistema carcerário brasileiro.

Nesse sentido, a Lei 12433/2011 alterou a Lei de Execuções Penais (LEP) a fim de atingir o objetivo de ressocialização do cidadão preso, através da educação. Com isso, a LEP passou a prever expressamente a possibilidade de remição da pena através do estudo na modalidade a distância (BRASIL, 2011).

Segundo Souza (2013), a utilização do ensino EaD no meio carcerário é uma vantagem para o Estado sob um ponto de vista de custo benefício, pois em uma primeira instância, a criação e instrumentalização dos ambientes de ensino demandam consideráveis investimentos. Porém, a manutenção é menos dispendiosa que o ensino convencional.

Além disso, como apontado por Reis (2015), o exercício do direito à educação pelo apenado exige uma logística muito complexa com grande aparato de segurança e o deslocamento até sala de aula é algo penoso para o preso e, nesse cenário, a EaD pode ter um papel transformador.

\section{Saúde}

Também é possível perceber a utilização dos AVAs nas Políticas Públicas voltadas à saúde e que essas políticas são fortemente afetadas por questões relacionadas à educação. Isto ocorre porque as ações no campo da saúde sofrem influência de variadas descobertas científicas, como o surgimento de novas drogas, o desenvolvimento de novas tecnologias e novas técnicas de combate às doenças.

Assim, muitas políticas de saúde são influenciadas por estudos e pesquisas 
desenvolvidos em cursos de graduação e pós-graduação da área de saúde. Estes cursos podem ser disseminados com facilidade através do ensino em EaD. Porém, não somente estudos avançados ou técnicas inovadoras são importantes para a promoção da saúde. A disseminação de informações simples e técnicas de baixo custo podem ser relevantes para combater ou evitar doenças. A transmissão de informações sobre alimentação, amamentação, atividades físicas, dentre outras, são de suma importância para a saúde de uma população.

Nesse contexto, é que o Ministério da Saúde passou a trata a questão da educação permanente como meio de transformar as práticas educativas da formação, da atenção, da gestão, de formação de políticas, de participação popular e de controle social no setor de saúde (Oliveira, 2007).

Santos, A. et al. (2017) citam que a educação permanente é uma educação crítica, reflexiva e participativa que representa a aprendizagem no trabalho com base nas situações do cotidiano da equipe. A EaD inserida nesse contexto, permite a troca de informações e experiências entre várias e equipes, de diversas localidades, não há necessidade de deslocamento dos profissionais, e dentre outras vantagens:

Conforme Brilhante et al. (2017), a dinâmica do trabalho dos profissionais de saúde, muitas vezes, demanda uma formação científica básica e acesso um saber universalizante e rápido, onde o trabalhador execute atividades reflexivas e críticas, com capacidade analítica e linguagens diversificadas e a vivência e a interação em ambientes virtuais educacionais podem consolidar as experiências vividas na atuação prática. Portanto, as atividades realizadas nos AVAs com a metodologia da EaD possibilitam o diálogo e a cooperação entre os profissionais dos serviços, atenção e formação e controle social, além de possibilitar que as instituições de ensino ampliem os conhecimentos de seus docentes (Oliveira, 2007)

\section{DESAFIOS E LIMITES DA UTILIZAÇÃO DA EAD E DOS AVAS NA IMPLEMENTAÇÃO DE POLÍTICAS PÚBLICAS}

A EaD, com o suporte dos AVAs, pode criar oportunidades e alternativas para levar a efeito as políticas públicas. Entretanto, ela encontra desafios e possui limitações e não pode ser vista como solução para todos os problemas sociais.

A EaD, em si, enfrenta muitos desafios, independentemente do fim para o qual é utilizada. A Escola Nacional de Administração Pública - ENAP (Escola, 2006) aponta que tais desafios devem ser trabalhados com muita determinação e que alguns deles 
são de ordem mais subjetiva e comportamental e outros são mais operacionais.

Os desafios de ordem subjetiva e comportamental, segundo ENAP (2006), são os desafios psico-sócio-culturais. Destes, os desafios psicológicos representam as rejeições, as desconfianças, os incômodos e o temor que o surgimento de um novo paradigma tende a causar. Dentre os desafios sociais, sob um enfoque da inclusão, da acessibilidade e da ética, tem-se a necessidade de não reproduzir as exclusões do ensino presencial e nem criar outras categorias de excluídos.

Os desafios culturais, por seu turno, são aqueles inerentes às necessidades de mudança de concepção ou forma de encarar o ensino. Consideram-se desafios culturais, a necessidade de desfazer o preconceito com o EaD. A necessidade de desenvolver materiais que possam dialogar com o aluno de modo a romper com 0 isolamento e a impessoalidade. Bem como, a necessidade de mudar o foco do ensino/aprendizagem do professor para o aluno e fazer com que este se torne cada vez mais autodidata. Ainda nos estudos de ENAP (2006), tem-se que os desafios mais operacionais são, os metodológicos, tecnológicos, legais, formação de equipe técnica e logística.

Além dos desafios gerais enfrentados pela $\mathrm{EaD}$, é de se perceber que somente cursos e treinamentos em EaD não podem resolver todos os problemas sociais e nem tornam desnecessárias outras ações governamentais a fim de tornar a vida em sociedade realmente digna e justa.

Por exemplo, quanto às políticas públicas de segurança, disponibilizar cursos aos seus agentes, não exime o Estado de investir em equipamentos para o corpo de bombeiros, armamentos para a polícia ou manter contingente adequado para manutenção da ordem e da segurança pública. Além disso, quando se pensa em disponibilizar cursos EaD no ambiente carcerário, tem-se que pensar muito na segurança do AVA, para que ele não seja utilizado como ferramenta de comunicação indevida, facilitadora de ações criminosas de apenados mal-intencionados.

Quanto às políticas públicas de saúde, tem-se que como limitações da $\mathrm{EaD}$, por exemplo, o fato de que a disponibilização de cursos e treinamentos não tornam desnecessários investimentos em hospitais, doação de remédios, compra de equipamentos e ambulâncias, etc. No que diz respeito à Educação Permanente em $\mathrm{EaD}$, preconizada pelo Ministério da Saúde, é interessante acrescentar o relato de Brilhante et al. (2017) que argumentam que mesmo considerando as potencialidades dos cursos de EaD, "não se pode negar a importância do encontro físico (das trocas, 
das discussões, do olhar...)". Citam, também, a importância das modalidades híbridas, onde se conjugam encontros presenciais periódicos com apoio dos AVAs.

Portanto, é de se perceber que, embora a troca de informações e a convivência em um AVA possam ser muito frutíferas para a aquisição de conhecimento, isto não substitui o encontro pessoal entre os profissionais de saúde e contato prático com o paciente. Por exemplo, um atendimento de emergência requer comunicação pessoal eficaz com troca de informações rápidas e precisas. Fazer um curativo ou sutura, assim como perceber e entender as reações do paciente a estes procedimentos, exigem habilidade e experiência que o AVA não é capaz de suprir.

Quanto aos servidores públicos, não bastar disponibilizar os cursos em AVAs. Há que se criar incentivos para que os treinamentos sejam cursados com bom aproveitamento. Por exemplo, as gratificações pagas aos servidores ou sua progressão na carreira poderiam ter influência dos cursos concluídos.

\section{CONSIDERAÇÕES FINAIS}

O presente trabalho abordou algumas das possibilidades de utilização dos AVAs e da EaD como suporte para implementar políticas públicas de diversos setores sociais. Dessa maneira, foi apresentada uma perspectiva mais ampla da utilização da EaD do que a que se tem de costume. Nesta visão, embora se reconheça a importância da EaD para a implementação de políticas públicas de educação, foram apontadas ações governamentais em outras áreas, como por exemplo, segurança pública e saúde. Apesar de tudo, não é possível olvidar que a EaD, em geral, encontra desafios que devem ser enfrentados e superados. Além disso, existem limitações no uso das tecnologias. Isso significa que disponibilizar cursos e treinamentos em AVAs, não pode ser encarado como desculpa para que os Governos deixem de realizar outras ações de interesse público.

Feitas estas ponderações, é possível constar que a EaD vem sendo largamente utilizada pelos entes estatais, em nosso país, para atingirem seus objetivos institucionais. Nesse contexto, muitos treinamentos e cursos são disponibilizados em AVAs a fim de conscientizar a população, treinar servidores públicos e disseminar informações e, dessa forma, implementar as políticas públicas do Estado.

O presente trabalho faz uma abordagem bastante global sobre a utilização dos AVAs e da EaD para implementar políticas públicas no Brasil. Porém, esta utilização é muito difundida e há espaço para outros estudos, mais específicos e mais aprofundados, 
assim como para estudos referentes a políticas públicas de outras áreas.

Importa, ao fim, entender que conhecer as potencialidades e os desafios da utilização dos AVAs e da EaD na implementação de políticas públicas contribui para que novas alternativas de formação e treinamento possam ser idealizadas pelos entes públicos. Isto favorece para que o conhecimento possa ser disseminado de maneira eficaz e para que se propicie melhorias na prestação dos serviços do Estado e melhorias nas condições de vida dos cidadãos usuários.

\section{REFERÊNCIAS BIBLIOGRÁFICAS}

BRASIL. Lei 12433, de 29 de junho de 2011. Altera a Lei no 7.210, de 11 de julho de 1984 (Lei de Execução Penal), para dispor sobre a remição de parte do tempo de execução da pena por estudo ou por trabalho. Disponível em: . Acesso em: 20 mar. 2018.

BRILHANTE; Ana Paula Cavalcante Ramalho; LEITÃO, Ilse Maria Tigre de Arruda; CARVALHO, Maria Raquel Rodrigues; LINARD, Cybele Façanha Barreto; LOURINHO, Lidia Andrade. Contribuições da Ferramenta EAD na Formação de Trabalhadores de Saúde: Visão dos Articuladores de Educação Permanente das Regionais de Saúde. Atas CIAIQ2017. Investigação Qualitativa em Saúde.Volume 2 . Disponível em: ; Acesso em: 19 mar. 2018

ESCOLA NACIONAL DE ADMINISTRAÇÃO PÚBLICA. Educação a distância em organizações públicas; mesa-redonda de pesquisa-ação. Brasília : ENAP, 2006. 200 p.

LIMA, Luciana Leite; D'ASCENZI, Luciano. Implementação de Políticas Públicas: perspectivas analíticas. revista de sociologia e política v. 21, ํo 48: 101-110 dez. 2013.

NUNES, Carolina Schmitt et al. Aprendizagem Organizacional e Ambientes Virtuais de Aprendizagem: um estudo sobre o Moodle. Revista de Informática Aplicada, v. 11, n. 1 , 2016

OLIVEIRA, Marluce Alves Nunes. Educação à Distância como estratégia para a educação permanente em saúde: possibilidades e desafios. Rev. Bras. Enferm, Brasília 2007 set-out;

PRODANOV, Cleber Crisitiano; FREITAS, Ernani Cesar. Metodologia do trabalho científico: métodos e técnicas da pesquisa e do trabalho acadêmico. 2. ed. - Novo 
Hamburgo: Feevale, 2013. Disponível em: . Acesso em: 02 mar. 2016.

REIS, Leandro da Silva. Educação a Distância, Tecnologia e LegislaçãoPrisional. Araranguá-SC. 2015

RUA, Maria das Graças. Políticas públicas. Florianópolis : Departamento de Ciências da Administração / UFSC; [Brasília] : CAPES : UAB, 2009. 130p. : il.

SANTOS, Ariane Gomes dos; COSTA NETO, Antônio Mariano da; ANDRADE, Daniele Benigno de; FIGUEIREDO, Kaio Alves. Importância de cursos a distância para qualificação profissional em saúde: relato de experiência. Revista Acadêmica de redes de cuidado em saúde, 2017. v.10.

SOUZA, Celina. Políticas Públicas: questões temáticas e de pesquisa. Caderno $\mathrm{CRH}$, Salvador, n. 39, p. 11-24, jul./dez. 2003.

SOUZA, Celina. Políticas Públicas: uma revisão da literatura. Sociologias, Porto Alegre, ano 8, no 16, jul/dez 2006, p. 20-45.

SOUZA, Janderson Paixão de. A Educação a Distância no Sistema Penitenciário sob o Suporte da Lei 12.433/11. Belém 2013. TCC

ZANELLA, Liane Carly Hermes. Metodologia de estudo e de pesquisa em administração. Florianópolis: Departamento de Ciências da Administração/ UFSC; [Brasília]: CAPES: UAB, 2009. 